\title{
On-off optical switching of the magnetic and structural properties in a spin-crossover complex
}

\author{
K. Kato and M. Takata \\ RIKEN SPring-8 Center, 1-1-1 Kouto, Sayo-cho, Sayo-gun, Hyogo 679-5198, Japan
}

Y. Moritomo ${ }^{\text {a) }}$

Department of Physics, University of Tsukuba, Tsukuba 305-8571, Japan

\author{
A. Nakamoto and N. Kojima \\ Graduate School of Arts and Sciences, University of Tokyo, Tokyo 153-8902, Japan
}

(Received 3 January 2007; accepted 7 April 2007; published online 14 May 2007)

\begin{abstract}
A photoexcitation is one of the promising external fields to control the material phases. Here, the authors have demonstrated that the magnetic and structural properties of a spin-crossover complex, $\mathrm{Fe}(\text { phen })_{2}(\mathrm{NCS})_{2}$ (phen=1,10-phenanthroline), can be reversibly switched by the on-off action of the continuous photoexcitation at the same temperature. The structural data suggest that the density of the high-spin $\mathrm{Fe}^{2+}$ in the photoinduced phase is about 0.88 . Suppressed atomic vibrations of the photoinduced phase exclude the conventional heating effect as the origin for the observed optical switching. () 2007 American Institute of Physics. [DOI: 10.1063/1.2736213]
\end{abstract}

The photoexcitation is one of the most promising methods to reversibly control the material phase/property of organic and metal-organic compounds, which may be utilized as an optical switching device. Among the materials, iron(II) spin-crossover complexes $^{1-8}$ is one of the most interesting systems, as they are known to show the photoinduced lowspin (LS) to high-spin (HS) transition. However, this lightinduced excited spin state trapping ${ }^{1}$ (LIESST) is a longfestering phenomenon, and we need a troublesome thermal annealing and/or another photoexcitation to restore the material. This is a serious limitation for the development of optical switching device based on the spin-crossover complexes. In this letter, we report on a fast on-off optical switching of the magnetic and structural properties of $\mathrm{Fe}(\text { phen })_{2}(\mathrm{NCS})_{2}($ phen $=1,10$-phenanthroline $)$ at the same temperature by a single continuous-wave laser at $532 \mathrm{~nm}$. There exists a threshold excitation light intensity $I_{\text {th }}$ for the on-off optical switching phenomenon, suggesting that some cooperative interaction among the photoinduced HS species plays a crucial role.

The spin-crossover complex, $\mathrm{Fe}(\text { phen })_{2}(\mathrm{NCS})_{2}$, consists of the neutral $\mathrm{Fe}$ (phen $)_{2}(\mathrm{NCS})_{2}$ molecules within the orthorhombic $(P b c n ; Z=4)$ cell. $^{9}$ In the $\mathrm{Fe}(\text { phen })_{2}(\mathrm{NCS})_{2}$ molecule, the iron(II) is surrounded by four $\mathrm{N}$ atoms belonging to 1,10-phenanthrolines and two $\mathrm{N}$ atoms of (NCS) ${ }^{-}$groups. The synthesis procedure of $\mathrm{Fe}(\text { phen })_{2}(\mathrm{NCS})_{2}$ was described elsewhere. ${ }^{9}$ The compound shows a thermally induced phase transition from the LS phase to the HS phase at $T_{C}=176 \mathrm{~K}$. The thermally induced phase transition is accompanied by a volume expansion, reflecting the elongation of the $\mathrm{Fe}-\mathrm{N}$ bond distances by $0.10-0.20 \AA$. At low temperature $(T<60 \mathrm{~K})$, the compound shows the LIESST phenomenon ${ }^{10}$ by the photoirradiation of a He/Ne laser $(633 \mathrm{~nm})$.

Figure 1(a) shows an example of the on-off optical switching of $\mathrm{Fe}(\text { phen })_{2}(\mathrm{NCS})_{2}$ at $100 \mathrm{~K}$, where no LIESST phenomenon is observed. The vertical axis is the density of the high-spin species $\left(n_{\mathrm{HS}}\right)$. The magnitude of $n_{\mathrm{HS}}$ is esti-

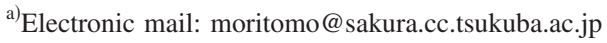

mated by the magnetic susceptibility measured in a Quantum Design magnetic properties measuring system (MPMS) superconducting quantum interference device magnetometer operated at $1000 \mathrm{Oe}$. The $n_{\mathrm{HS}}$ value shows a clear binary response to the on-off action of the continuous-wave laser irradiation at $532 \mathrm{~nm}$. The transition speed is about $10 \mathrm{~s}$. Hereafter, we will call the phase under photoirradiation as "on phase." In this phase, the creation process of the HS species overwhelms the thermal relaxation process of them. In Fig. 1(b), we plotted the $n_{\mathrm{HS}}$ value in the on phase against the excitation powder $(I)$. The $n_{\mathrm{HS}}$ value begins to increase when $I$ reaches a threshold value $\left(I_{\text {th }}=6 \mathrm{~mW} / \mathrm{mm}^{2}\right)$, and then reaches around 0.8 at $I=20 \mathrm{~mW} / \mathrm{mm}^{2}$. Such a threshold behavior is absent in the conventional LIESST phenomenon. Désaix et al. ${ }^{11}$ reported a similar threshold behavior, but with much slower transition time of order of hour, in a mixed crystal $\mathrm{Fe}_{0.5} \mathrm{Co}_{0.5}(\mathrm{btr})_{2}(\mathrm{NSC})_{2} \mathrm{H}_{2} \mathrm{O}$. They attributed the behavior to the cooperative effect of the relaxation. In order to explain much faster switching time as observed in this letter, however, we need an additional cooperative effect in the creation process of the HS species. We think that the internal pressure $^{6}$ induced by the photoinduced HS species, whose
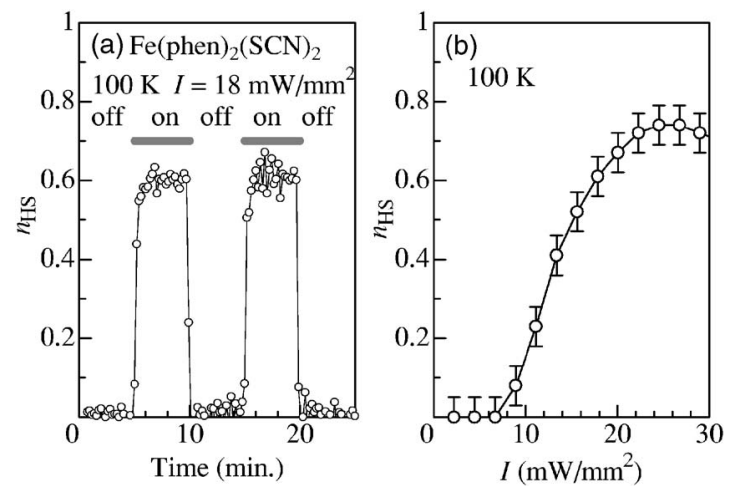

FIG. 1. (a) On-off optical switching of the density of the high-spin species $\left(n_{\mathrm{HS}}\right)$ measured at $100 \mathrm{~K}$. The gray horizontal bar represents the on-off action of the excitation light at $532 \mathrm{~nm}$. (b) Excitation power density (I) dependence of $n_{\mathrm{H}}$ in the "on phase" at $100 \mathrm{~K}$. 


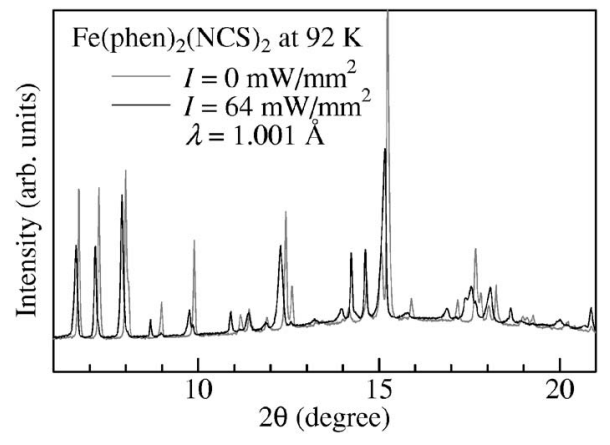

FIG. 2. X-ray powder diffraction patterns of $\mathrm{Fe}(\text { phen })_{2}(\mathrm{NCS})_{2}$ at $92 \mathrm{~K}$ under photoexcitation $\left(I=64 \mathrm{~mW} / \mathrm{mm}^{2}\right.$ : black curve $)$ and without photoexcitation (gray curve).

ionic radius $(=0.74 \AA)$ is much larger than that $(=0.61 \AA)$ of the $\mathrm{LS} \mathrm{Fe}^{2+}$, causes a structural phase transition into the HSrich phase. This argument is further supported by the fact that the cell volume of the photoinduced phase is much larger than that of the LS phase (vide infra).

In order to reveal the structural feature of the on phase, we have performed a synchrotron-radiation $\mathrm{x}$-ray powder diffraction measurement at the SPring-8 BL02B2 beamline. ${ }^{12}$ A $532 \mathrm{~nm}$ laser beam was weakly focused onto the capillary with a convex lens $(f=20 \mathrm{~cm})$; the laser spot size (about $2 \mathrm{~mm})$ is larger than the $\mathrm{x}$-ray beam size $\left(1 \times 0.5 \mathrm{~mm}^{2}\right)$. The reflections were collected on an imaging plate, installed in a large Debye-Scherrer camera. The reflections were collected on an imaging plate in the $2 \theta$ range of $3^{\circ}-76^{\circ}$. Figure 2 shows a part of the powder diffraction pattern at $92 \mathrm{~K}$ : black (gray) curve represents the patterns with (without) photoexcitation. Even though the photoexcitation considerably changes the powder diffraction patterns, the pattern change is reversible for a repeated on-off action of the laser irradiation. The sample under photoexcitation is stable for more than $11 \mathrm{~h}$, without any deterioration of the diffraction pattern. The gray curve without photoexcitation is well reproduced by the Rietveld refinement with the single orthorhombic ( $P b c n ; Z$ $=4)$ phase, that is, the LS phase. On the other hand, we need an additional photoinduced phase to reproduce the black curve. The space group of the photoinduced phase is found to be the same as that of the LS phase. We ascribe the additional phase to the on phase, as observed in Fig. 1(a). Here, we emphasize that the formation of the photoinduced phase cannot be ascribed to the conventional thermal heating effects. Because the degree of the thermal atomic vibrations of the photoinduced phase, which was estimated by the socalled Wilson plot, ${ }^{13}$ is nearly the same as that at $92 \mathrm{~K}$ and is much smaller than that at $260 \mathrm{~K}$.

Figure 3(a) shows the cell volume ( $V$ ) of the LS phase (filled circles) and the photoinduced phase (open circles) against $I$. The $V$ value of both the phases shows negligible change against $I$. The cell volume $\left(V=2.28 \mathrm{~nm}^{3}\right)$ of the photoinduced phase is about $4 \%$ larger than that $\left(=2.20 \mathrm{~nm}^{3}\right)$ of the LS phase, reflecting the larger ionic radius of the $\mathrm{HS} \mathrm{Fe}^{2+}$. In Fig. 3(b), we plotted the mass fraction $(s)$ of the photoinduced phase. As shown by the eyeguided broken line, the formation of the photoinduced phase shows the threshold behavior, consistently with the magnetic behavior [see Fig. 1(b)].

Here, let us compare the microscopic structure of the on phase with the other HS phases, that is, the low-temperature Downloaded 06 Feb 2009 to 130.158.56.188. Redistribution subject
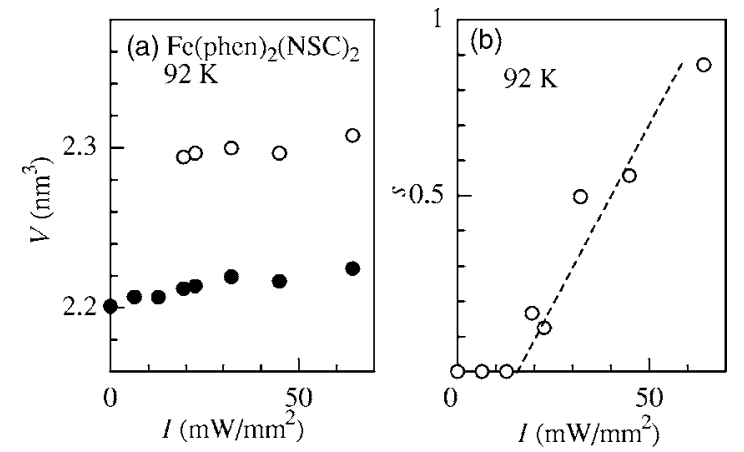

FIG. 3. (a) Cell volume ( $V)$ of $\mathrm{Fe}(\text { phen })_{2}(\mathrm{NCS})_{2}$ at $92 \mathrm{~K}$ against excitation power density $(I)$. Closed and open circles stand for the LS phase and the on phase, respectively. (b) Mass fraction ( $s$ ) of the on phase against $I$. A broken straight line is merely the guide for the eyes.

LIESST phase and the thermally induced HS phase. We listed in Table I the geometrical features of the $\mathrm{FeN}_{6}$ octahedron of $\mathrm{Fe}(\mathrm{phen})_{2}(\mathrm{NCS})_{2}$ molecule. The $\mathrm{FeN}_{6}$ octahedron in the HS phase has larger distortion $(\Sigma)$ and larger volume $(v)$ as compared with those of the LS phase. At the bottom of Table I, we listed the relative volume $(v / V)$ of the $\mathrm{FeN}_{6}$ octahedron normalized by the cell volume. In spite of the 3\% thermal shrinkage, the magnitude of $v / V(=0.00635)$ in the LIESST phase at $30 \mathrm{~K}$ (Marchivie et al. ${ }^{10}$ ) is nearly the same as that $(=0.00639)$ at $260 \mathrm{~K}$. This is probably because the LIESST phase is a metastable HS phase, which can be produced also by the thermal quenching. Here, we emphasize that the magnitude of $v / V(=0.00622)$ in the on phase is smaller than the other HS phases. If we postulate a linear relation between $n_{\mathrm{HS}}$ and $v / V, n_{\mathrm{HS}}$ of the on phase is estimated to be about 0.88 . Such a suppressed $n_{\mathrm{HS}}$ value should be ascribed to the dynamical nature of the on phase, where the creation process of the HS species balances with the thermal relaxation process of them.

Finally, let us investigate the charge density distribution of the $\mathrm{Fe}(\mathrm{phen})_{2}(\mathrm{NCS})_{2}$ molecule. Figures 4(b)-4(d) show

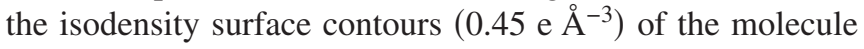
determined by the maximum entropy method (MEM) Rietveld analysis ${ }^{14-17}$ on the $\mathrm{x}$-ray powder diffraction patterns. The isodensity surface contour is sharp at $92 \mathrm{~K}$ [the LS phase: Fig. 4(b)] and in the on phase [Fig. 4(c)], while it is

TABLE I. Geometry of the $\mathrm{FeN}_{6}$ octahedron of $\mathrm{Fe}(\mathrm{phen})_{2}(\mathrm{NCS})_{2} \cdot d_{\mathrm{Fe}-\mathrm{N}_{i}}$ $(i=1,2$, and 3$)$ is the $\mathrm{Fe}-\mathrm{N}_{i}$ bond distance. $\sum$ is defined by the sum of the absolute values of the deviation from $90^{\circ}$ of the 12 cis angles of the $\mathrm{FeN}_{6}$ octahedron. $V$ and $v$ are the cell volume and the volume of the $\mathrm{FeN}_{6}$ octahedron, respectively. These values were determined by the Rietveld analysis of the x-ray powder diffraction patterns. $\mathrm{N}_{1}$ and $\mathrm{N}_{2}$ atoms are located on 1,10-phenanthroline, while $\mathrm{N}_{3}$ are on $\mathrm{NCS}^{-}$ion.

\begin{tabular}{rrrrr}
\hline \hline & \multicolumn{3}{c}{ HS phase } & \\
\cline { 2 - 4 } & $30 \mathrm{~K}^{\mathrm{a}}$ LIESST & $92 \mathrm{~K}$ on phase & $260 \mathrm{~K}$ & \multicolumn{1}{c}{\begin{tabular}{c} 
LS phase \\
\hline$d_{\mathrm{Fe}-\mathrm{N}_{1}}(\AA)$
\end{tabular}} \\
$d_{\mathrm{Fe}-\mathrm{N}_{2}}(\AA)$ & 2.177 & $2.197(3)$ & $2.218(1)$ & $2.006(2)$ \\
$d_{\mathrm{Fe}-\mathrm{N}_{3}}(\AA)$ & 2.184 & $2.197(5)$ & $2.218(2)$ & $1.976(3)$ \\
$\sum($ degree $)$ & 2.006 & $2.046(5)$ & $2.071(4)$ & $1.930(4)$ \\
$V\left(\AA^{3}\right)$ & 64 & 64 & 64 & 38 \\
$v\left(\AA^{3}\right)$ & 2242 & 2308 & 2319 & 2199 \\
$v / V$ & 14.24 & 14.35 & 14.82 & 11.32 \\
\hline \hline
\end{tabular}

$\overline{{ }^{\mathrm{a}} \text { Reference } 10 .}$
to AlP license or copyright; see http://apl.aip.org/apl/copyright.jsp 

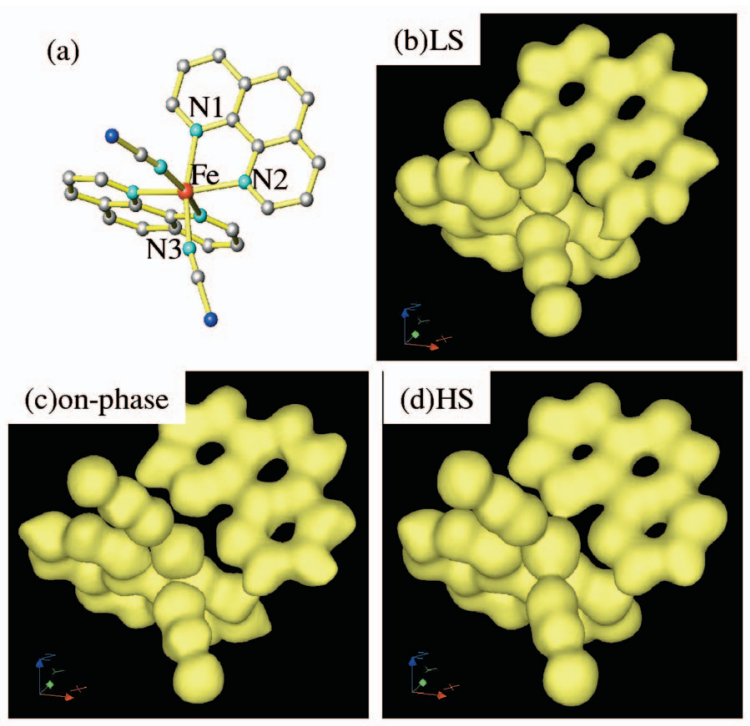

FIG. 4. (Color) (a) Ball and stick picture of the $\mathrm{Fe}(\mathrm{phen})_{2}(\mathrm{NCS})_{2}$ molecule. Isodensity surface contour $\left(0.45 \AA^{-3}\right)$ of the $\mathrm{Fe}(\mathrm{phen})_{2}(\mathrm{NCS})_{2}$ molecule in (b) the LS phase at $92 \mathrm{~K}$, (c) the on phase at $92 \mathrm{~K}$, and (d) the HS phase at $260 \mathrm{~K}$, determined by the MEM/Rietveld analysis.

rather blurred at $260 \mathrm{~K}$ [the thermally induced HS phase: Fig. 4(d)]. This again indicates that the degree of the thermal atomic vibrations of the photoinduced phase is nearly the same as that at $92 \mathrm{~K}$. Here, we emphasize that the respective $\mathrm{Fe}(\text { phen })_{2}(\mathrm{NCS})_{2}$ molecule in the photoinduced phase repeats the photoexcitation and thermal relaxation processes. The iron ion of the on phase [Fig. 4(c)] is more isolated as compared with the LS phase [Fig. 4(b)], reflecting the longer $\mathrm{Fe}-\mathrm{N}$ bond distance.

In conclusion, we demonstrated the on-off optical control of the magnetic and structural properties of a molecular solid. The photoinduced phase, in which the creation process of the HS species balances with the thermal relaxation process of them, exists only under photoexcitation. Based on the structural analysis, we concluded that the photoinduced phase is a cold phase with suppressed HS density and longrange periodicity. Thus, the photoexcitation is a promising external field to control the material phase, especially when it is coupled with material parameters such as the spin state or the internal pressure.

This work was supported by a Grant-In-Aid for Scientific Research from the Ministry of Education, Culture,
Sports, Science and Technology and Japan Science and Technology Agency (CREST "X-ray Pinpoint Structural Measurement-Development of the Spatial- and Timeresolved Structural Study Technique for Nano-materials and Devices"). The synchrotron-radiation x-ray powder diffraction experiments were performed at the SPring-8 BL02B2 beamline with approval of the Japan Synchrotron Radiation Research Institute (JASRI).

${ }^{1}$ A. Hauser, J. Jeftić, H. Romstedt R. Hinek, and H. Spiering, Coord. Chem. Rev. 190, 471 (1999).

${ }^{2}$ Y. Ogawa, S. Koshihara, K. Koshino, T. Ogawa, C. Urano, and H. Takagi, Phys. Rev. Lett. 84, 3181 (2000).

${ }^{3}$ T. Tayagaki and K. Tanaka, Phys. Rev. Lett. 86, 2886 (2001).

${ }^{4}$ N. O. Moussa, G. Molnár, S. Bonhommeau, A. Zwick, S. Mouri, K. Tanaka, J. A. Real, and A. Bousseksou, Phys. Rev. Lett. 94, 107205 (2005).

${ }^{5}$ X. J. Liu, Y. Moritomo, T. Kawamoto, A. Nakamoto, and N. Kojima, J. Phys. Soc. Jpn. 72, 1615 (2003).

${ }^{6}$ Y. Moritomo, M. Kamiya, A. Nakamura, A. Nakamoto, and N. Kojima, Phys. Rev. B 73, 012103 (2006).

${ }^{7}$ H. Liu, A. Fujishima, and O. Sato, Appl. Phys. Lett. 86, 122511 (2005).

${ }^{8}$ S. Bonhommeau, G. Molnár, A. Galet, A. Zwick, J. A. Real, J. J. McGarvey, and A. Bousseksou, Angew. Chem., Int. Ed. 44, 4069 (2005).

${ }^{9}$ B. Gallois, J. A. Real, C. Hauw, and J. Zarembowich, Inorg. Chem. 29, 1152 (1990).

${ }^{10}$ M. Marchivie, P. Guionneau, J. A. K. Howard, G. Chastanet, J. F. Létard, A. E. Goeta, and D. Chasseau, J. Am. Chem. Soc. 124, 194 (2002).

${ }^{11}$ A. Désaix, O. Roubeau, J. Jeftic, J. G. Haasnoot, K. Boukheddaden, E. Codjovi, J. Linarés, M. Nogués, and F. Varret, Eur. Phys. J. B 1998, 183.

${ }^{12}$ E. Nishibori, M. Takata, K. Kato, M. Sakata, Y. Kubota, S. Aoyagi, Y. Kuroiwa, M. Yamakawa, and N. Ikeda, Nucl. Instrum. \& Methods 467468, 1045 (2001).

${ }^{13}$ See EPAPS Document No. E-APPLAB-90-077718 for magnitude of the thermal atomic vibrations estimated by the Wilson plot. This document can be reached via a direct link in the online's HTML reference section or via the EPAPS nomepage (http://www.aip.org/pubserves/epaps.html).

${ }^{14}$ M. Takata, E. Nishibori, and M. Sakata, Z. Kristallogr Z. Kristallogr. 216, 71 (2001).

${ }^{15}$ M. Takata and M. Sakata, Acta Crystallogr., Sect. A: Found. Crystallogr. 52, 287 (1996).

${ }^{16}$ H. Tanaka, M. Takata, E. Nishibori, K. Kato, T. Ishii, and M. Sakata, J. Appl. Crystallogr. 35, 282 (2002).

${ }^{17}$ The diffraction data were collected for $11 \mathrm{~h}$ at $92 \mathrm{~K}$ (the LS phase and the on phase), $260 \mathrm{~K}$ (the HS phase). The number of the structural factors derived by the Rietveld analysis was 672, 700, and 706 for the LS phase, the on phase, and the thermally induced HS phase, respectively. The maximum (minimum) $d$ values were 8.6 (1.2), 8.7 (1.2), and $8.7 \mathrm{~A}(1.2 \mathrm{~A})$ for the off state, the on state, and the HS phases. The MEM analyses were carried out with a program ENIGMA (Ref. 16) using $132 \times 100$ $\times 172$ pixels. The $R_{F}$ factors based on the MEM charge densities are $3.5 \%, 2.7 \%$, and $4.3 \%$ for the LS phase, the on phase, and the HS phase, respectively. 